Han, X., Zhou, Q., Shi, W.\& Yang, S.(2020). Online Learninga in Vocational Education of China during

COVID-19: Achievements, Challenges, and Future Developments.

Journal of Educational Technology Development and Exchange, 13(2), 61-82

\title{
Online Learninga in Vocational Education of China during COVID-19: Achievements, Challenges, and Future Developments
}

\author{
Xibin Han \\ Qian Zhou \\ Wanruo Shi \\ Shuyuan Yang \\ Tsinghua University
}

\begin{abstract}
COVID-19 has challenged education systems globally. Traditional teaching and learning activities of more than 1,300 vocational colleges and nearly 11,000 vocational high schools in China have had to be paused and transformed into an online mode. A study had been conducted to trace the unprecedented change which would provide reflections on policies and practical experience worthy of reference for the follow-up development of online vocational education in China and other countries in the world. The study used two methods to collect data: (1) delivering questionnaires to 767 schools, 17009 teachers, 270,732 students, and (2) gathering 110 institute cases from 21 provinces and 170 curriculum cases from 14 provinces. The result showed that vocational institutions coped with the pandemic's outbreak through online learning and achieved the overall goal of "Not Going to School but Classes still Ongoing." Further, vocational institutions have faced problems and challenges of online learning in practice training and internship, organization, and technical environment. The development of vocational education in the information era requires thinking about the system-driven reform path and online learning strategy and putting it into action.
\end{abstract}

Keywords: Online Learning, Vocational Education, COVID-19, Education Transformation 


\section{Introduction}

The COVID-19 pandemic has impacted education at all levels in various ways. Teachers and students all over the world have worked together to face this challenge. Thus, online education during the pandemic has become a trending research topic. For instance, in the face of this sudden transition, researchers are concerned about teachers' and students' perspectives and strategies for online education (Hebebci et al., 2020; Spoel et al., 2020; Moawad, 2020). Due to the closure of schools and universities, national, institutional, and pedagogical responses have been widely discussed (Flores \& Gago, 2020; Johnson et al., 2020; Supriyanto et al., 2020). Besides, a growing body of literature recognizes the pandemic's impact on medical students' clinical training (Choi et al., 2020; Pather et al., 2020; Soled et al., 2020). However, a great many studies have focused on the field of higher education (Mishra et al., 2020; Toquero, 2020), primary or secondary education (Christakis et al., 2020), and teacher education (Carrillo \& Flores, 2020; Moorhouse, 2020). However, in this body of research, most researchers have failed to focus on vocational education during the pandemic.

The impact of the pandemic on vocational education is significant. Facing the unprecedented challenges, vocational institutions had to stop or delay their experiential courses that often required practice training and internship, which accounted for many of their syllabi. Take vocational education in China, for instance, during the pandemic. More than 1,300 vocational colleges and nearly 11,000 vocational high schools have rearranged plans and launched online courses in a very short time. Many obstacles and problems have been exposed because of the rapid transition. Meanwhile, rich practical experience and strategies of transitioning to online education in vocational institutions have grown, worthy of reference for vocational education in China and other countries in the world.

Therefore, this study focuses on the field of vocational education in China, aiming at exploring the following two questions:

(1) What are the achievements of online education in vocational education in China during the pandemic?

(2) What are the problems, challenges, and future development of online education in vocational education?

Based on the two research questions, the research team has organized nationalscale questionnaires to investigate the process of online learning in vocational institutions. Examining case studies has also been conducted. Furthermore, achievements, challenges, and possible future development are discussed in the paper.

\section{Method}

This study mainly used two methods to collect data: questionnaires and case studies. The questionnaires targeted institutional administrators, teachers, and students. The case studies examined institutions and courses. The questionnaires helped describe the basic situation of online learning in vocational education during the pandemic, and the case study focused more on specific details.

\subsection{Questionnaires and case study}

After rounds of expert consultation, questionnaires for school administrators, teachers, and students were developed. The structure of the questionnaires is shown in 
Table 1. A random sample of vocational institutions had been recruited from the Digital Campus of Vocational Institutions and cooperative institutions of the research team that included over 32 provinces of China (including Xinjiang Production and Construction Corps). Email, MMS, etc. contacted the administrators of each sampled school. Then the teacher and student questionnaires were distributed with school administrators as a hub. The questionnaires were opened from March 19th to March 26th, released by a questionnaire platform (http:// www.wjx.cn).

Table 2.1.1. The structure of three questionnaires

\begin{tabular}{lll}
\hline School questionnaire & Teacher questionnaire & Student questionnaire \\
\hline Organizations \& management & Models of teaching & Learning support \\
Technical service & Instructional design & Learning attitude \\
Engagement & Teacher-student interaction & Learning preference \\
Learning support & Online training \& simulation & Learning content \\
Evaluation & & Internship \\
Extracurricular activities \& social forces & & Satisfaction \\
\hline
\end{tabular}

Relevant cases of online learning in vocational institutions were provided by institutions or collected through public news search. Based on that, two types of vocational institutions during the pandemic were constructed: one is from institutions, and the other is from online courses. In the research process, the research team classified, encoded, summarized, abstracted, and summarized all case texts from aspects of schools, teachers, and students to deduct relevant research conclusions.

\subsection{Data collection}

\subsubsection{Questionnaire data}

- Questionnaire data of schools

Seven hundred sixty-seven valid school questionnaires were collected, covering 29 provinces (municipalities and autonomous regions included) in China. East China and Northeast China accounted for a relatively high proportion of valid questionnaires, $33 \%$, and $20 \%$, respectively. No valid questionnaires were received from Tibet and Qinghai provinces. There were 376 questionnaires of vocational high schools, accounting for $49 \%$, and 391 vocational colleges, accounting for $51 \%$.

The participation of online education of the surveyed institutions is shown in Figure 2.2.1, in which the proportion of students' participation is the highest, while the proportion of courses and teachers is relatively low. However, no matter from students, teachers, courses, or majors, about $80 \%$ of vocational institutions' online education coverage is more than half. 


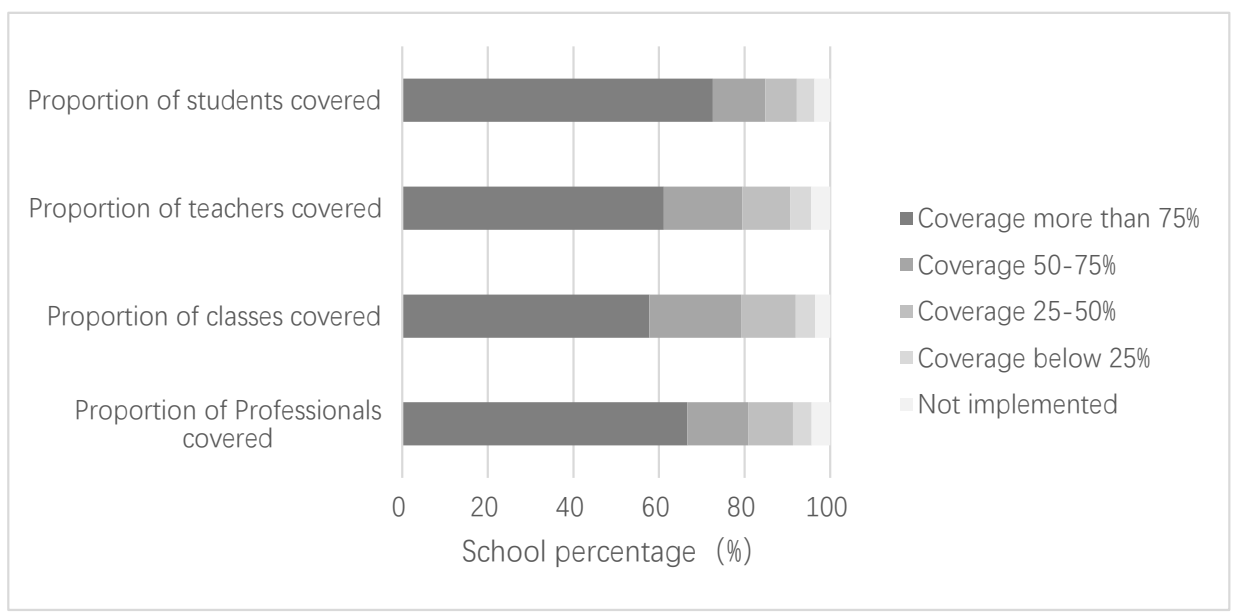

Figure 2.2.1. The participation of online education

- Questionnaire data of teachers

Seventeen thousand nine valid teacher questionnaires were collected from 31 provinces (municipalities and autonomous regions included) in China. Liaoning province,
Shandong province, Shaanxi province, and Jiangsu province accounted for $14 \%, 12 \%$, $9 \%$, and $9 \%$ of the total sample, respectively, which were the top four highest proportions. The demography and workload of surveyed teachers are illustrated in Table 2.2.1.

Table 2.2.1. Demography and workload of teachers

\begin{tabular}{lll}
\hline Demography \& workload & Label & Percentage(\%) \\
\hline \multirow{2}{*}{ School } & Vocational high schools & 42.12 \\
& Vocational colleges & 57.88 \\
\hline \multirow{2}{*}{ Gender } & Male & 36.9 \\
& Female & 63.1 \\
\hline \multirow{3}{*}{ Age } & Below 30 & 19.72 \\
& $31-40$ & 40.84 \\
& $41-50$ & 26.69 \\
& More than 51 & 12.75 \\
\hline \multirow{3}{*}{ Number of courses taken } & 1course & 55.75 \\
& Two courses & 27.7 \\
& Three courses & 7.91 \\
& More than four courses & 8.64 \\
\hline
\end{tabular}


- Questionnaire data of students

Two hundred seventy-nine thousand two hundred fifty-four valid student questionnaires were collected, of which boys accounted for $48 \%$, and girls accounted for $52 \%$. There were 211,143 questionnaires for students of vocational colleges accounting for $76 \%$, and 68,111 questionnaires for students of vocational high schools accounting for $24 \%$.

Surveyed students were scattered across the country. Among them, Liaoning province,
Shanxi province, and Shandong province having the most significant number of valid questionnaires, while Shanxi province, Qinghai province, Jiangxi province, Ningxia province, and Tibet having the fewest valid questionnaires (less than $0.1 \%$ ). There were a minimal number of students' questionnaires from Hong Kong, Macau, and Taiwan. The subsequent analysis did not include these students' answers, considering the proportion was extremely low. The following figure shows the distribution of students' schools in Mainland China (see Figure 2.2.2).

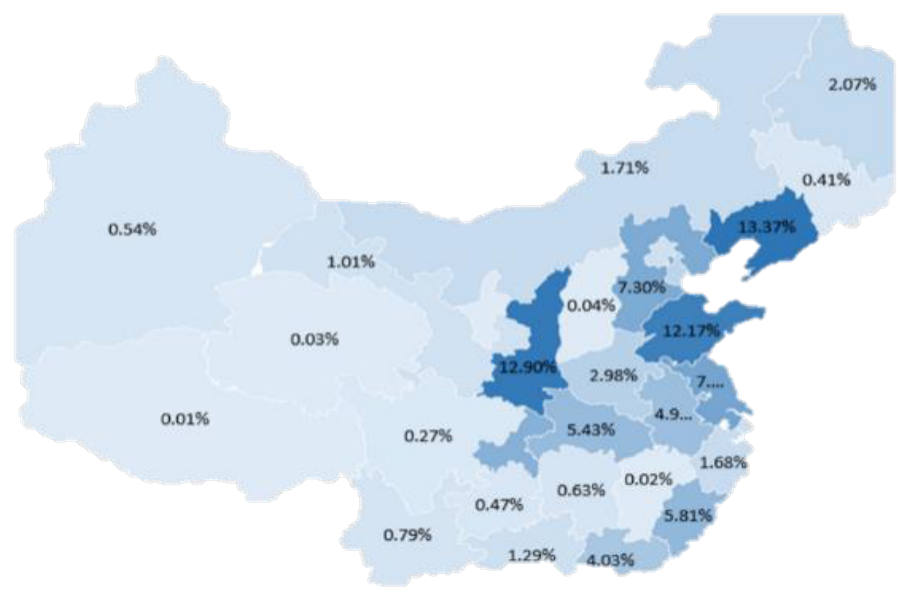

Figure 2.2.2. The distribution of students'schools in Mainland China

Most of the students live in rural areas (34\%). The proportion of students located in prefecture-level cities, counties, and townships was similar $(17 \%, 18 \%$, and $14 \%$, respectively), and only a few students were located in municipalities (8\%) and provincial capital cities $(9 \%)$.

Sixty-seven thousand three hundred and eighty-nine students were graduates. Eightyseven percent of the graduates participated in online learning during the pandemic, while $13 \%$ did not. The follow-up analysis removed students who did not participate and analyzed the situation of 270,732 vocational students who participated in online learning.

In terms of the number of courses taken, students with seven courses and above accounted for 37\%, 5-6 courses accounted for $38 \%$, and only $7 \%$ took $1-2$ courses. The number of students with previous online learning experience $(57 \%)$ last semester was slightly more than that of students without online learning experience $(43 \%)$. 


\subsubsection{Case Data}

\section{- Cases of vocational institutions}

A total of 106 institutional cases of online education were collected. There are 82 vocational colleges, accounting for $77 \%$, and 24 vocational high schools, accounting for $23 \%$. The case schools cover 19 provinces (municipalities and autonomous regions included) in China.

\section{- Cases of online courses}

A total of 64 significant cases of online courses were collected. Fifty-nine online courses from vocational colleges accounted for $92 \%$, and five online cases from secondary vocational high schools accounted for $8 \%$. The relatively large proportion of courses included 17 compulsory courses (accounting for $27 \%$ ), ten courses in public management and service professionals (accounting for 16\%), and eight courses in information technology professionals (accounting for 13\%).

\section{Result}

\subsection{The result of the school questionnaire and cases}

\subsubsection{Organizations and management}

In the face of a pandemic, most vocational colleges and high schools adjusted their spring semester plans. According to the questionnaire, more than half of the schools rearranged the spring semester instructional plans $(74 \%)$, made teacher training plans of online teaching $(62 \%)$, provided guidelines for online teaching $(51 \%)$, and made quality assurance plans (55\%). Also, some schools set up expert teaching groups (39\%) and learning support groups $(30 \%)$.

In terms of instructional plans, most schools rearranged their teaching timetable and suspended or postponed practice training and internship schedules during the pandemic. The types of online courses reflecting this rearrangement or suspension included: (1) more theoretical courses, fewer practice training courses, and a few courses that achieved integration of theory and practice; (2) more specialized compulsory courses, fewer public compulsory courses, and most elective courses were suspended; and (3) internship in most schools were delayed. Moreover, online course preparation was a process of teamwork. Teachers cooperated in preparing lessons and discussing together based on open educational resources. Some schools adjusted their assessment methods of student performance. For example, students could get credit through online tests or submitting study papers and design works. Besides, most schools thoroughly considered the visual fatigue, long-term sitting, and time zone difference in central and western China. Thus, schools shortened the online class time, adjusted the proportion of online and offline study hours, and prepared flexible schedules.

\subsubsection{Technical service}

As for technical services, most schools $(61 \%)$ had adequate infrastructure preparations that could successfully carry out online learning. Although a small number of schools had not built sufficient infrastructure, they still tried their best to organize online learning by sharing resources. A majority of schools integrated both school learning platforms and opened online learning platforms. Much attention was paid to both online learning hardware and software. More than half of schools constructed the temporary digital learning resources by teachers $(64 \%)$ and teaching teams $(52 \%)$. Sharing resources between schools $(42 \%)$ also achieved remarkable results. 


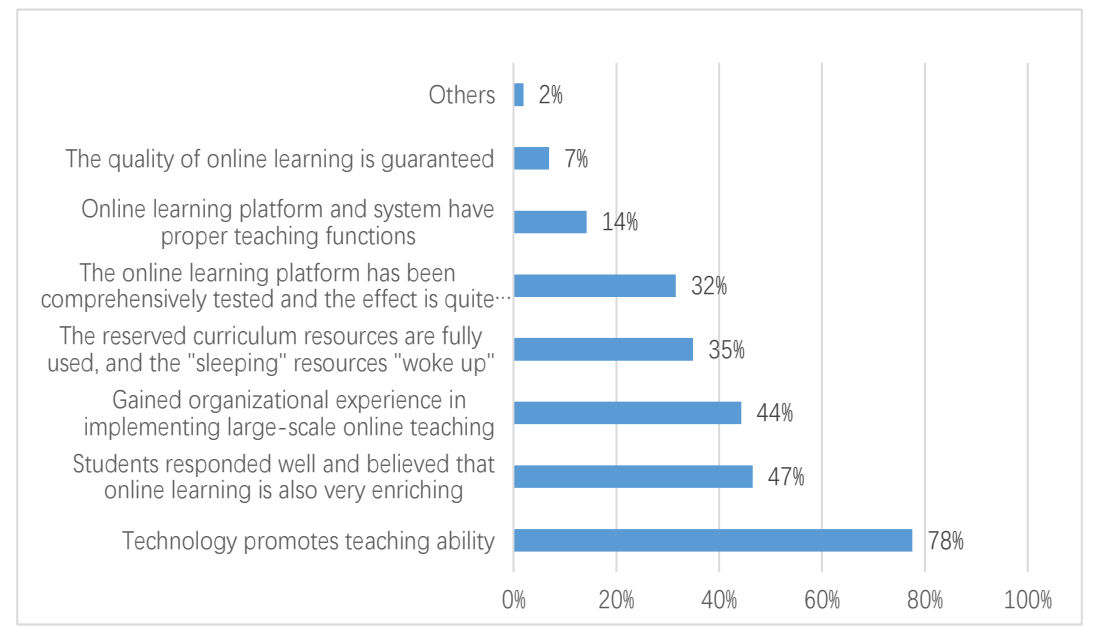

Figure3.1.1. The most satisfying aspects of online learning

\subsubsection{Engagement and learning support}

Online learning required the organization, management, and teacher-student investment and corresponding capital investment. According to the questionnaire, in response to the funding situation, a considerable number of schools invested much money in teaching support services $(65 \%)$, teacher training $(64 \%)$, platform software $(57 \%)$, digital resources $(53 \%)$, hardware $(52 \%)$, and student online learning support $(50 \%)$. The proportion of schools that invested funds in virtual simulation and skill training was relatively low, with only $36 \%$. In terms of the teachers' and students' engagement, $80 \%$ of schools have more than half of the teachers participating in online learning, and $85 \%$ of schools have more than half of the students participating. Regarding the most satisfying aspects of online learning, $78 \%$ of the schools reported that technology promoted teaching ability, and $47 \%$ of the schools reported that students responded well and believed that online learning was enriching

Teachers became the leading force in online learning. Most schools (62\%) provided various assistance to students through temporary teams established by teachers. A small number of schools sought help from companies (39\%) and experts $(27 \%)$. Besides, student mutual assistance became an essential highlight of online learning during the pandemic. More than one-third (34\%) of students formed online learning teams.

Almost all schools (97\%) considered students' inconvenience in online learning and provided various solutions. Most schools (57\%) added a new consulting team composed of head teachers, teaching assistants, teachers, and supplier technicians that specifically responded to student technical problems. More than half of the schools rearranged their courses $(56 \%)$ and carried out mental health counseling (52\%) to support students' online learning. There were also a small number of schools providing students with online tariff support $(35 \%)$, changing the tutoring method $(35 \%)$, and extending deadlines $(36 \%)$ such as make-up exams.

\subsubsection{Evaluation}

The results of the questionnaire showed 
that evaluation during the pandemic mainly focused on teaching (62\%), courses $(48 \%)$, platform $(36 \%)$, and administration $(31 \%)$. The evaluation content mainly focused on the teaching process and teaching effect; the former mainly focused on teachers' and students' behaviors, teaching methods, teaching activities, students' online attendance, and students' participation. The latter focused on teachers' and students' satisfaction, teachers' perception, and students' learning experience. A small number of schools have not issued relevant evaluation programs $(16 \%)$. In terms of evaluation subjects, most feedback came from teaching supervisors (59\%), followed by students' feedback (58\%), teachers' self-evaluation ( $47 \%)$, feedback from teachers $(40 \%)$, and feedback from experts $(29 \%)$. A small number of schools used other evaluation objects $(2 \%)$, and a few had no means for evaluation (4\%). Case studies showed that evaluation occurred on two levels in most schools: (1) school level and (2) department level. The school-level evaluation was mainly organized by the educational administration office and the department of teaching quality control. The department directors mostly undertook the quality supervision and evaluation on the department level.

In terms of the evaluation method, case studies showed that 41 vocational institutions reported specific online evaluation methods, mostly an optimized combination of four methods (see Figure 3.1.2). These methods included online supervising, platform-databased evaluation, random checking, and survey of teachers and students. Half of the schools $(51 \%)$ used a single evaluation method, and their frequency was as follows: online supervising (20\%), platform-data-based evaluation $(15 \%)$, the survey of teachers and students $(15 \%)$, and random school checking $(2 \%)$. Among schools that adopted multiple evaluation methods, the most commonly used was a combination of platform-data-based evaluation and survey of teachers and students $(20 \%)$, followed by online supervising and platform-data-based evaluation (10\%).

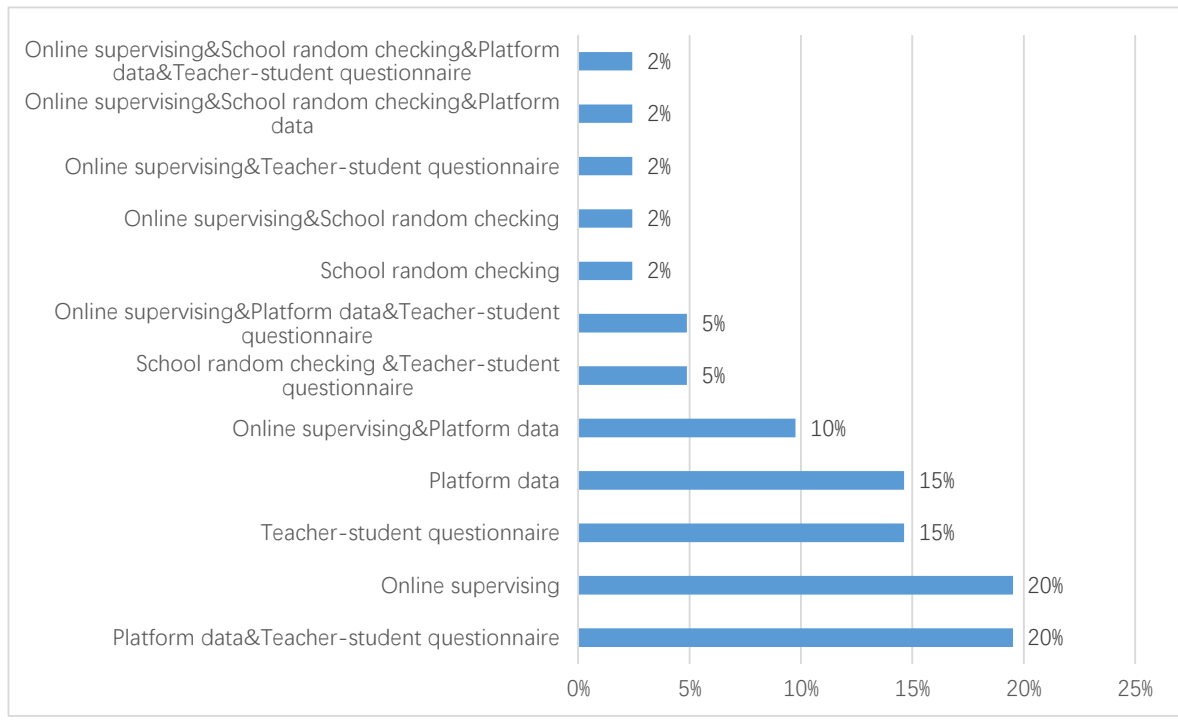

Figure 3.1.2. Online learning evaluation method 
As far as evaluation results, $73 \%$ of the schools submitted evaluation results in the form of daily reports $(9 \%)$, weekly reports $(14 \%)$, monthly reports $(5 \%)$, or other periodic reports $(18 \%)$, among which $27 \%$ of schools not only provided feedback of evaluation results but also used them as the basis for promoting teaching. Also, some schools $(27 \%)$ only objectively described their evaluation results without reporting their feedback on evaluation results.

3.1.5 Extracurricular activity arrangement and partnership

Most schools promoted ideological and political education through online class meetings, while some schools integrated anti-pandemic and patriotism into classes and achieved positive results. Some schools considered a reduction in travel activities during the pandemic; they launched exercisein-home activities to protect students' health. As for teachers and students' mental health, some schools carried out online counseling activities to guide students' mental health development. Some schools launched a series of moral education activities to help students rationally plan their learning activities at home through various strategies, such as career education, legal education, housework activities, and network security education, to strengthen moral education in many ways. The questionnaire found that the most exchanged content between vocational institutions and off-campus partners was IT support services $(52 \%)$, followed by learning resource sharing $(47 \%)$, and online teaching experience and technology exchanges (45\%). Ensuring online learning was not affected had been the principal business value of schools during the pandemic. However, the schoolcompany cooperation of counseling and emergency experience sharing was relatively low $(26 \%)$, and nearly $6 \%$ of schools have no exchanges with off-campus partners. In the face of tremendous pressure during the pandemic, relying on one school alone was much pressure. If various resources could be integrated between schools and social forces, it could guarantee regular online learning. Regarding the most satisfying aspects of online learning, $44 \%$ of schools obtained large-scale online learning experiences. Thirtyfour percent of schools planned to reorganize the institutional framework for online learning from temporary to regular support, and $15 \%$ of schools planned to improve the ability to organize large-scale online education as their main improvement measures after the pandemic.

\subsection{The result of the teacher questionnaire and cases}

\subsubsection{Models of teaching}

About preferred method of teaching courses, the questionnaire responses resulted: $52 \%$ of teachers chose live broadcast, $53 \%$ chose live broadcast and interaction on LMS, $32 \%$ chose video recording, $64 \%$ chose selfstudy on the platform and Q\&A in social media, and $3 \%$ chose other forms. Live broadcast became the first choice because of its format similar to face-to-face teaching, direct-used content, and simultaneous teacherstudent interaction. However, due to the Internet's widespread applications, self-study methods based on the platform and social media also became the leading alternative approaches. Judging from the results in the questionnaire, one teacher tended to adopt different methods in teaching. Specifically, methods could be summarized into three types: live broadcast as the mainstay, preview + live-broadcast Q\&A, and self-study+ Q\&A in social media.

\subsubsection{Instructional design}


For preparing lessons, the questionnaire showed that more than $90 \%$ of teachers had built unique resources for online learning during the pandemic, of which 53\% were self-built, and $41 \%$ were co-built with other teachers (see Figure 3.2.1). The questionnaire also showed that most courses in vocational institutions $(62 \%)$ were practice training courses, which were difficult to achieve teaching goals through pure online. Teachers needed to reposition the teaching goals and chose theoretical and informative content.

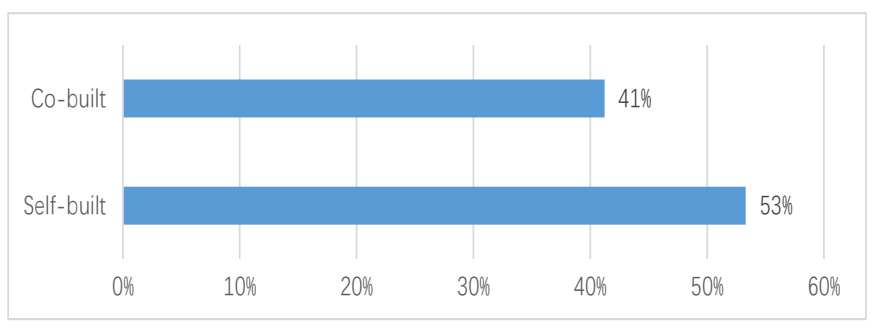

Figure 3.2.1. Unique resources for online learning

For preparing students, online learning required students to have high selfmanagement, adjustment capabilities, and proper engagement. Teachers needed to strengthen the interaction and feedback based on students' characteristics in the online learning environment.

Regarding the teaching method, the most frequently used teaching methods were the inquiry-based approach and projectbased approach, accounting for $38 \%$ and $36 \%$, respectively (see Figure 3.2.2). Demonstration-imitation, brainstorming, and collaborative learning methods also had many applications, accounting for $28 \%, 18 \%$, and $18 \%$, respectively. Besides, teachers also considered online evaluation methods and emergency response plans.

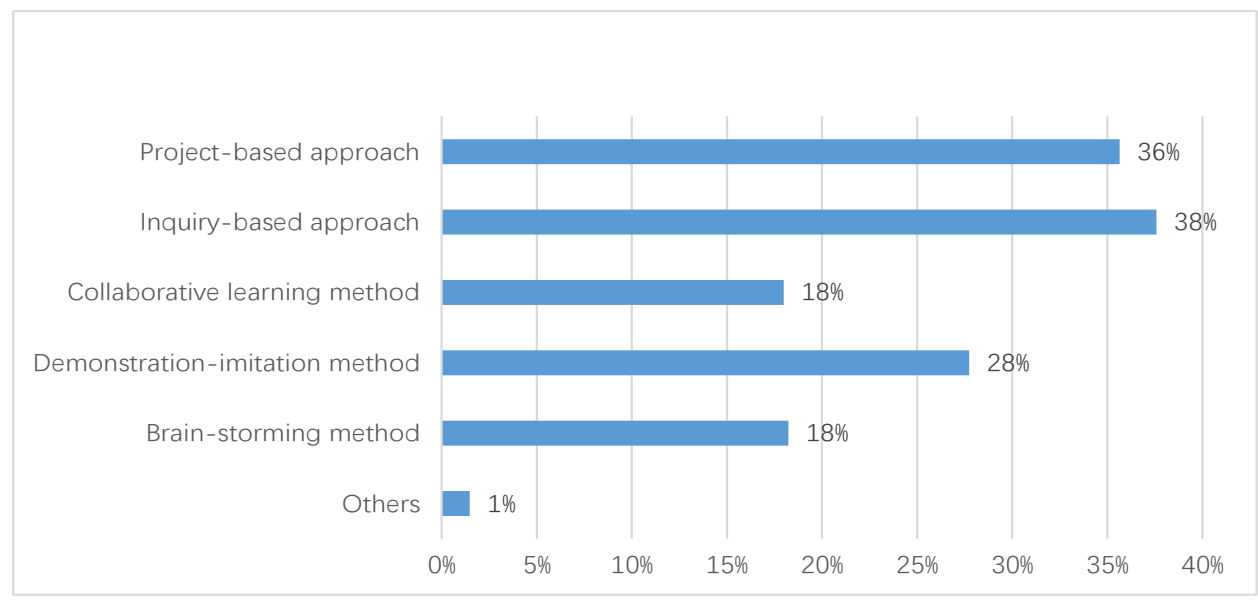

Figure 3.2.2. The most frequently used teaching methods 


\subsubsection{Teacher-student interaction}

Roll-call questions and in-class tests were the main interactive methods online. Group discussions, presentations, and competitions were applied as well. Some teachers organized diversified interactive activities, for example, using barrage, voting, brainstorming, and roleplaying. Through various interactions, student participation in online courses reached more than $90 \%$, and $60 \%$ of teachers reported that the quality of online interaction was relatively high.

\subsubsection{Online training and simulation}

The questionnaire showed that $27 \%$ of vocational institutions postponed their practice training courses during the pandemic. Students watched skill-training videos in $37 \%$ of the training courses. Thirty-seven percent of the courses actively explored new training methods in the online environment, including online training, virtual reality simulation, home training, and real-life display in the workplace.

\subsection{The result of the student questionnaire and cases}

\subsubsection{Learning support}

Schools and parents provided various support for students' online learning. According to the questionnaire results, a majority of parents provided support for students' online learning. Sixty-nine percent of parents strongly supported students' online learning and supervised their learning. Only
$2 \%$ of the parents showed an unsupportable attitude towards online learning. Case studies indicated that students also received learning support from schools regarding learning resources, teacher-student interaction, financial aid, counseling, and more.

Most students' network conditions and equipment could guarantee their learning needs. Seventy-nine percent of the students illustrated that network conditions at home were sufficient to support their online learning, but $22 \%$ of them found it not enough to be supported.

Almost all students had learning devices, while $0.05 \%$ of students reported no devices. The vast majority (95\%) of students used mobile phones for online learning; $30 \%$ used laptops for online learning, and $8 \%$ used tablet computers. Forty-six percent of students had two or more devices for online learning.

Technical preparation and support were some of the most significant prerequisites for students' online learning (see Figure 3.3.1). The questionnaire results showed that the primary source of support for students' technical preparation was the school's specialized technical training $(55 \%)$ and personalized help from teachers $(51 \%)$ during the pandemic. Peer coaching accounted for $30 \%$, and learning sources from the Internet or books accounted for $29 \%$. Besides, $22 \%$ of students said that the school had previously carried out online learning activities, making the transition from face-to-face to online learning more seamless. 


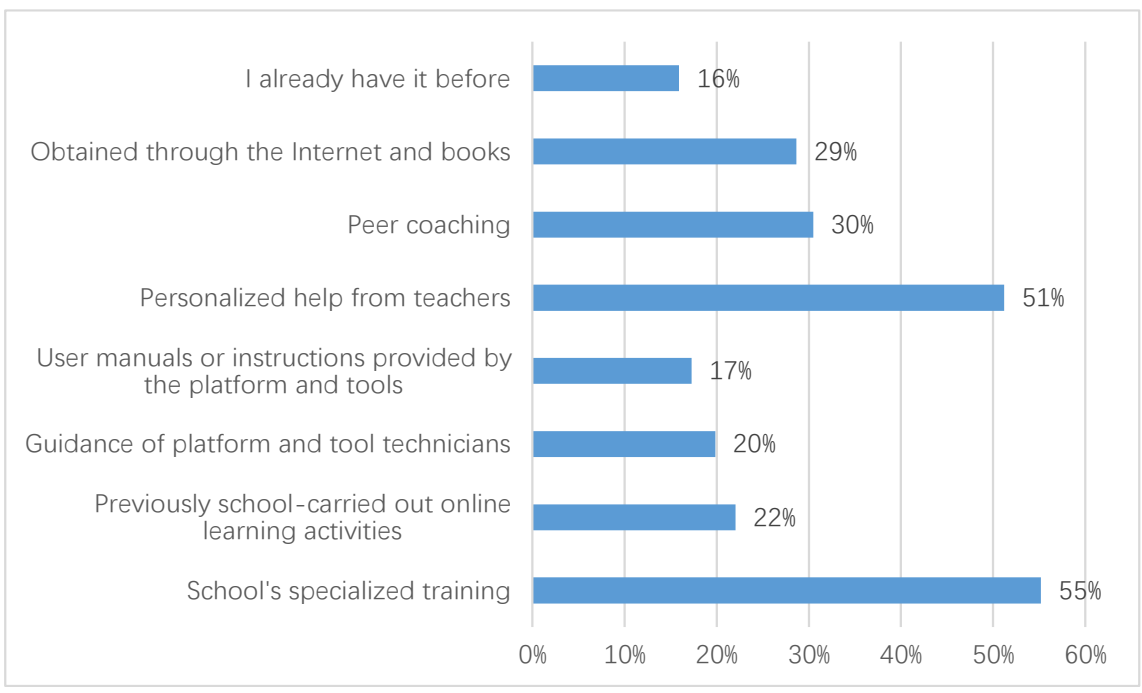

Figure 3.3.1. Source of support for students'technical preparation

\subsubsection{Learning attitude}

Most students had a positive learning attitude, mainly reflected in electronic device preparation, learning resources and notes, and other learning materials before class. They participated in online courses on time during class, and they completed homework and tests on time after class. Furthermore, students devoted more time to online learning and controlled their online entertainment time well.

Sixty percent of the students surveyed stated that they always prepared well for class, $25 \%$ of the students often made some preparation for class, while $5 \%$ of students occasionally or never prepared for class, as shown in Figure 3.3.2.

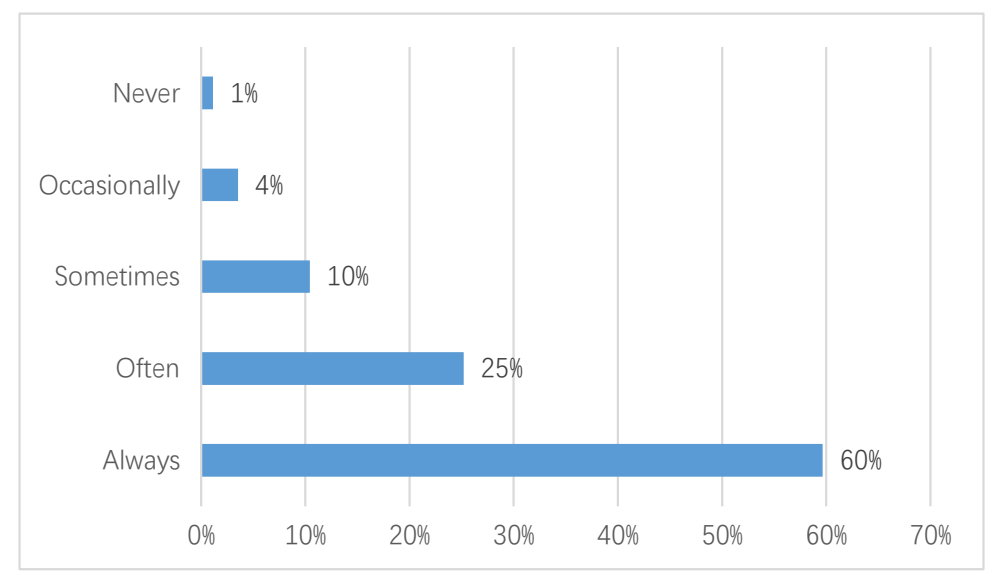

Figure 3.3.2. How often do students prepare for class 
Seventy-six percent of the students surveyed stated that they could attend online courses on time, $19 \%$ of students were late for class occasionally. Five percent of students had a negative attitude towards learning and were often late for class. Ninety-six percent of the students surveyed were able to complete the homework and tests on time, and only fewer students failed to complete their homework on time.

During the pandemic, $40 \%$ of students said that the online learning time per day was 4-6 hours, accounting for the most significant proportion. Thirty-four percent of students illustrated that online learning was 2-4 hours per day. Sixteen percent of the students spent more than 6 hours of online study per day, and less than $10 \%$ of the students studied less than 2 hours per day. It could be concluded that during the pandemic, vocational students spent a relatively long time on online learning every day with a roughly estimated overall mean of 4 or more hours.

Comparing online learning during the pandemic with face-to-face learning in the last semester before the pandemic, $66 \%$ of students did not believe that the time in watching movies and playing games online became longer. Although online was longer, students' online entertainment time did not increase, as illustrated in Figure 3.3.3.

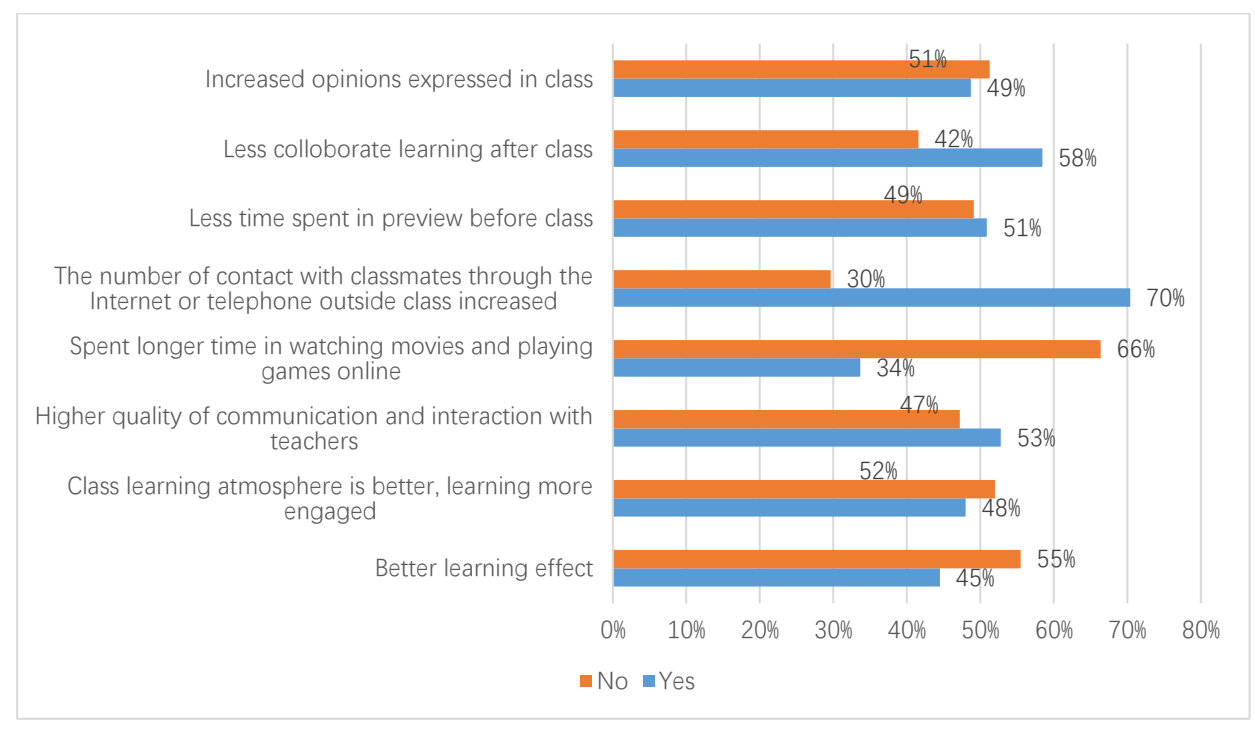

Figure 3.3.3. Comparison between online learning during the pandemic and traditional learning last semester

\subsubsection{Learning preference}

Different students had different preferences for online learning. Students could carry out personalized learning in an online learning environment with the support of schools and teachers.
Most students preferred no more than 40 minutes for one class in terms of a live broadcast duration. Regarding the total length of online live classes every day (assuming 40 minutes was one class hour), $54 \%$ of students expected 1-3 class hours per day, which accounted for the most. Forty-one percent 
of students expected 4-6 class hours per day. Only less than $5 \%$ of students expected seven class hours or more per day. In general, the total hours of live broadcast should not be too much every day.

Given the proportion of teachers' lecture time to the overall class, $60 \%$ of students believed it should account for half of the whole class. Twenty-one percent of students surveyed preferred that lecture time accounts for three-quarters of the class, and $19 \%$ preferred one-quarter.
When considering students' favorite online teaching models, more than half of the students (accounting for 58\%) preferred live broadcast for class. This was followed by the combination of the online learning platform and live broadcast (accounting for $31 \%$ ), video recording (accounting for $28 \%$ ), and the combination of the online learning platform and social media tools such as WeChat and QQ (accounting for 24\%). Finally, online resources designated by the teacher together with live broadcast (accounting for 17\%) were preferred (see Figure 3.3.4).

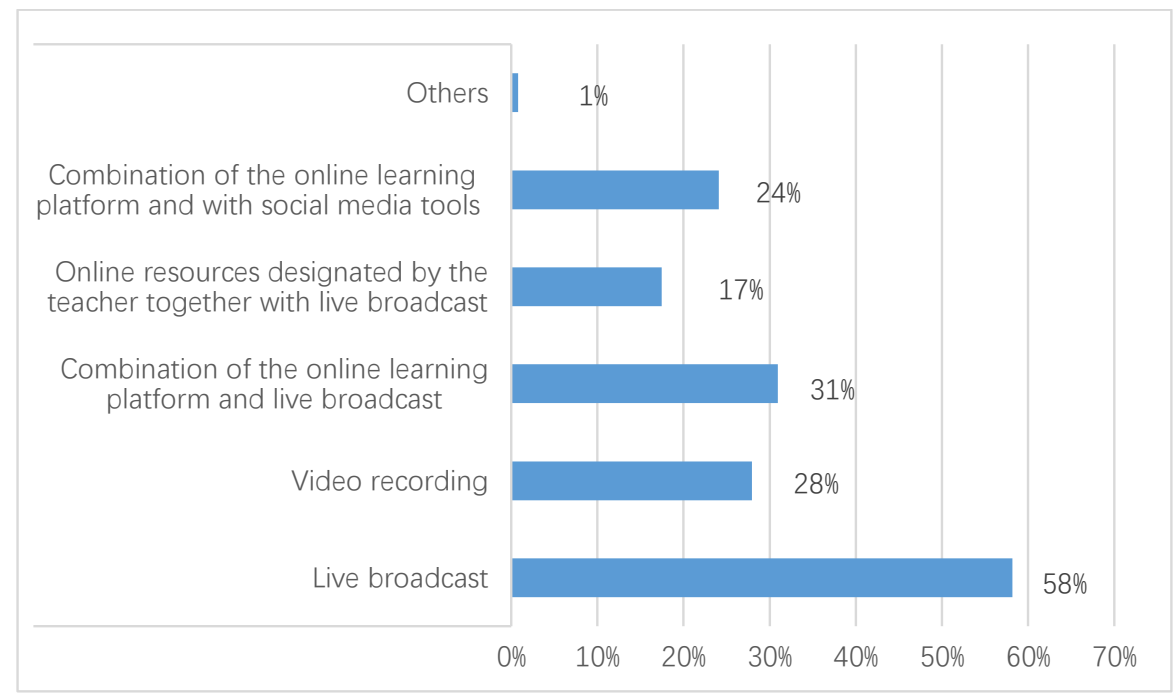

Figure 3.3.4. Students'favorite online class models

The most often used functions of online learning platforms by students were Homework submission (76\%), Looking through learning materials (67\%), Doing the tests $(56 \%)$, and Watching live broadcast $(43 \%)$. The Replay function was less used $(17 \%)$. The function of Discussion posts also accounts for a low proportion (12\%). As for teachers and students' different preferences, students preferred to interact with teachers while having the Q\&A (Question \& Answer) session during live broadcast, and teachers preferred to answer questions on social media platforms. Compared with the asynchronous Q\&A posted in the discussion area, both teachers and students preferred real-time synchronous interaction (see Figure 3.3.5). 


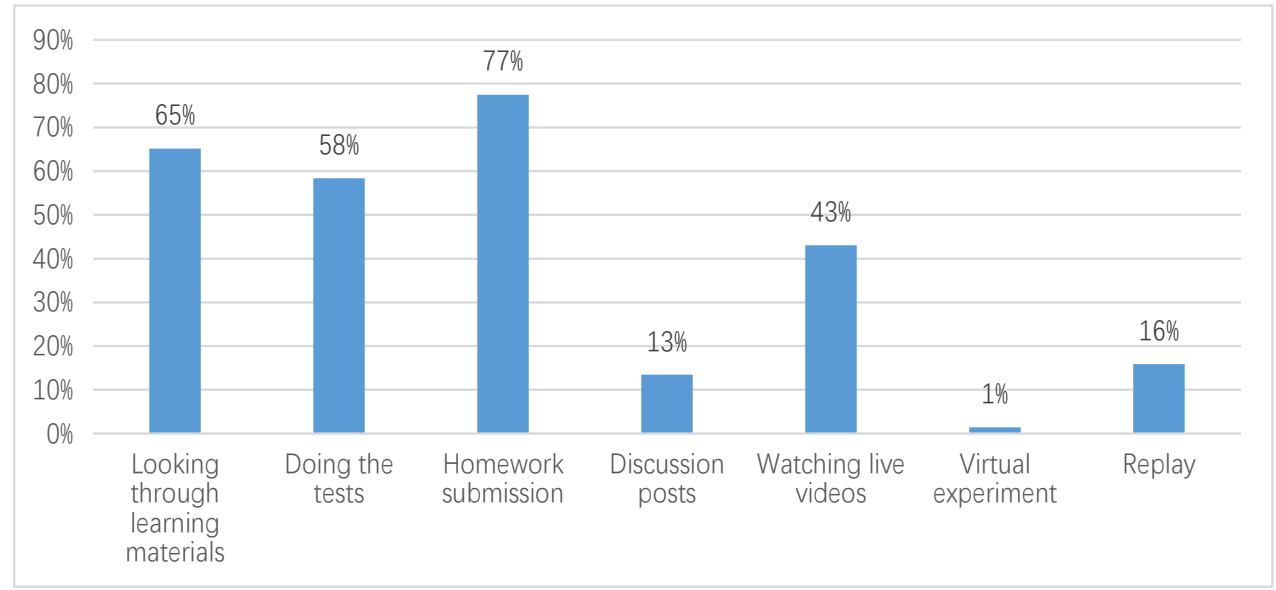

Figure 3.3.5. Online learning platform features most commonly used by students

Students' online learning methods depend on teacher's models of online teaching. It was necessary for teachers to comprehensively consider network conditions, requirements of courses, teacher-student interaction, course costs, students' learning process, and learning data analysis. During the pandemic, schools and teachers had diversified teaching methods, learning resources, teacher-student interaction, and teaching models to support personalized learning.

\subsubsection{Learning content}

During the pandemic, most vocational institutions adjusted learning content to adapt to students' home learning. The proportion of training courses for online learning was relatively small. Most of the training courses were carried out by adjusting the teaching methods based on home premises or equipment, and a small number of them used simulation training software or a combination of the above two.
The case study showed that online learning was almost entirely rolled out in vocational institutions during the pandemic. Except for the postponement of some training courses and physical education courses, most of the courses were carried out and proceeded smoothly. While carrying out online courses, the graduation work for 2020 graduates also progressed in an orderly manner. For instance, some schools adjusted their graduates' workplace learning plans, and instructors provided online guidance through a college student graduation design (thesis) management system.

More than a quarter of students said that online training was a weak part (see Figure 3.3.6). Courses involving training part and practical training required accounted for $26 \%$, and those not involved accounted for $17 \%$. Twenty-four percent of the courses involved had no relevant training resources provided online. Thirty-three percent of the courses only allowed students to watch relevant videos but did not require practice training. 


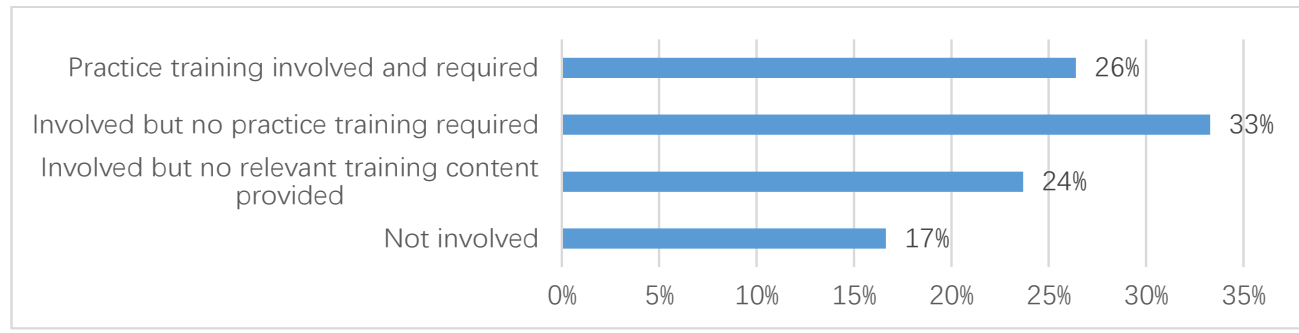

Figure 3.3.6. Online training courses during the pandemic

The questionnaire results showed that in order to achieve practice training goals, $55 \%$ of the courses used training venues or equipment at home (such as computer software, sports, art design, English listening, etc.). Twenty-four percent of the courses used simulation software for online training, and $20 \%$ of the courses provided simulation software, together with training venues and equipment (see Figure 3.3.7).

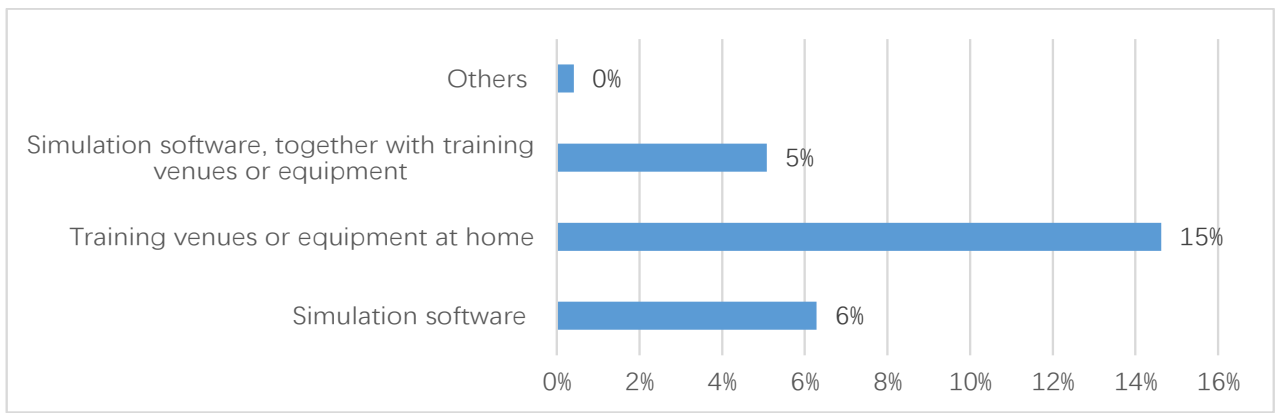

Figure 3.3.7. Approaches used to realize practice training

Case studies indicated that many vocational institutions actively took measures to remedy the lack of practice training. Schools cooperated with enterprises and mobilized multiple forces to carry out training courses in the following four ways: (1) uses virtual simulation and other similar means, (2) included school-enterprise cooperation and application of enterprise online platform, (3) conducted a live broadcast of practical cases, and (4) held online cooperation to form a cross-professional team. The last method was used to form cooperation patterns of school- enterprise collaboration, school-government collaboration, home-school collaboration and remedy the deficiencies of online teaching and learning.

\subsubsection{Internship}

For students who were waiting for a job, vocational institutions focused on the three following aspects: (1) ensured students' health and safety during the pandemic and implement a daily report system for students' physical conditions; (2) carried out surveys to 
learn about students' employment intentions, expand employment channels, and establish a positive employee attitude, in order to promote students' employment; and (3) supervised and promoted students' graduation design and thesis work and improved learning quality at workplace. Institutions made full use of the online workplace-learning guidance and management platform and related learning resources to strengthen pre-service training. They also made full use of the company's online training platform and resources to carry out various skill training activities for students waiting for work. Institutions made full use of online thesis platforms to provide online thesis guidance and defense.

\subsubsection{Satisfaction}

By comparing online learning interaction during the pandemic with face-to-face ones in the previous semester, it could be found that $53 \%$ of students believed that the quality of interaction improved, and $70 \%$ of students thought their contact with classmates through the Internet or telephones after the class increased (see Figure 3.3.3).

As shown in Figure 3.3.8, students were delighted with course guidance information in the online learning environment (53\%) and some strategies such as roll call and sign-in for supervising learning (51\%). The online course playback (45\%) and abundant learning resources $(29 \%)$ were other important factors to support students' online learning. Thirtythree percent of students believed that online learning increased the flexibility of learning time. Some students also suggested that online learning could save the time of learning.

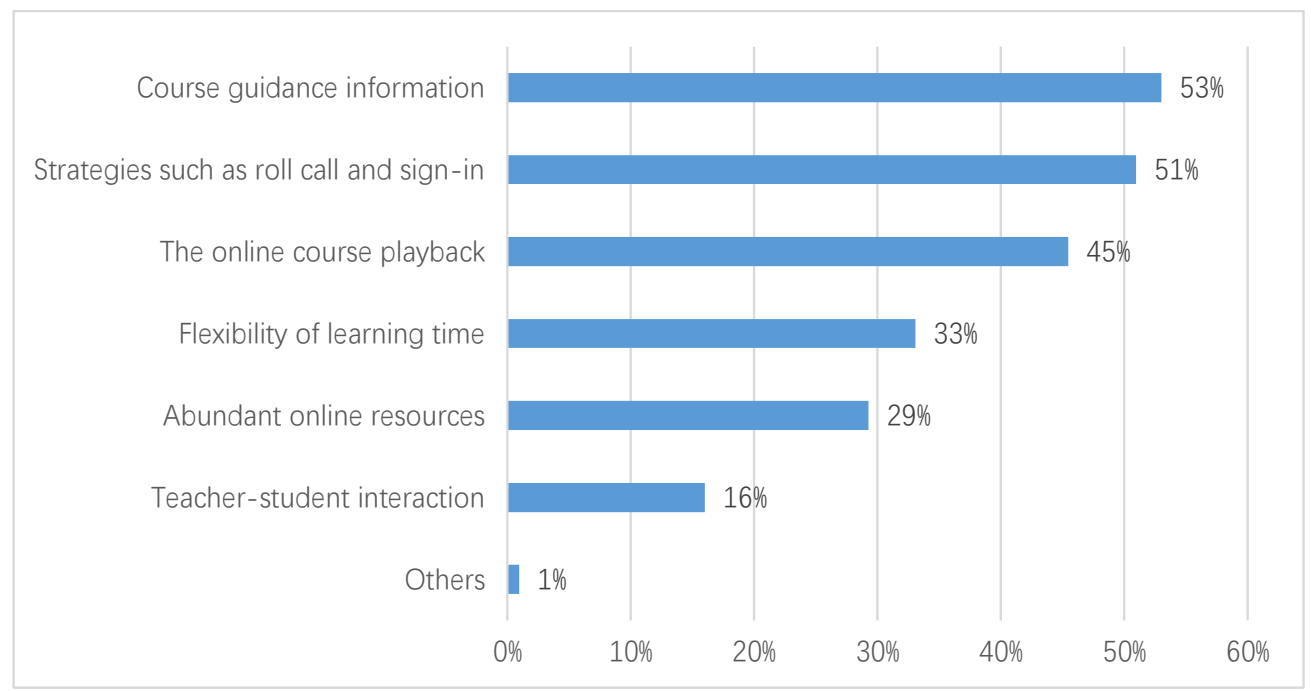

Figure 3.3.8. Students'satisfaction with online learning

\section{Discussion}

\subsection{The achievements of online learning}

The achievement of online learning during the pandemic in vocational institutions can be summarized from the results. Online learning in vocational institutions ensured success 
for the overall development of vocational education. According to the data from some provinces' education departments, it showed that the proportion of opening online courses in some provinces reached a high level. Teachers' participation was more than $70 \%$, and students were more than $78 \%$. On the other hand, the satisfaction of online learning of parents and students was at $87 \%$. Online courses ensured "Not Going to School but Classes still Ongoing" during the pandemic.

Secondly, online learning improved the organization, management, and technical service. To ensure online learning went orderly, different departments of vocational institutions worked together and formed working groups. Everyone performed their duties, cooperated, and carried out tasks. Most schools set up temporary institutions to ensure the operation of online teaching. Besides, school leaders and teachers provided many services, such as student learning support service teams, which strengthened studentcentered awareness. At the same time, schools kept encouraging students to help each other, forming a mutual aid community of studentteacher-organization. Online learning also strengthened infrastructures and services. The most school provided strong technical support for the development of online learning. For example, support included improving the campus network's bandwidth, the server's carrying capacity, the application software of online learning, providing online teaching resources, and ensuring the cooperation of internal and external technical teams.

Moreover, online learning supported the development of online extracurricular activities. In addition to online courses, vocational institutions also carried out some online extracurricular activities during the pandemic to explore online campus culture construction. Last but not least, online learning laid the foundation for the deep integration of technology and education. During the process of carrying out online learning, vocational institutions have accumulated organizational experiences and a deeper understanding of online education. A certain proportion of schools hope to take this online learning as an opportunity to continuously deepen the innovation of teaching mode and promote the deep integration of information technology and education.

\subsection{Problems and challenges of online learning}

Vocational institutions faced some problems and challenges. First, the practice training courses and internship were significantly impacted, and the online practice training and internship model needed to be explored. More than a quarter of schools have not carried out practice training courses at all, and more than one-third of schools have not launched internships at all. Moreover, some schools lacked concepts and direction of online learning. Most schools aimed to reduce the impact on teaching and learning; only a few realized the online learning could innovate the model of personnel training and enhance the quality. Besides, teachers and students needed to improve literacy and application ability of technical service. According to the questionnaire results, only one-third of schools considered the main factors that affected online learning: the teacher's unawareness of concept and incompetence of technical service. More than half of schools planned to develop online teaching ability of teachers after the pandemic. On the other hand, more than half of the schools thought the primary factors attributed to students' lack of methods and online learning habits.

The online learning organization was not complete, and the regular online learning 
organization was yet to be built. Some schools have not considered whether the newly added online working groups should be kept. Furthermore, some schools lacked systematic evaluation and continuous research of online learning. More than half of schools paid attention to the online evaluation process but did not explain the evaluation results and related processing. Most schools neither provided evaluation feedback to the results regularly nor followed up with further tracking after the evaluation.

Moreover, the learning support system needed to be improved, and teachers' online teaching incentive policy needed to be built. Less than half the schools formulated student support and security policies, not to mention teaching incentive policies. Among the 106 cases, only five institutions mentioned the policy documents of students' learning security, and only two referred to the policy documents of teacher incentive.

A weak technical environment was also a difficulty. A few schools nether had any technology guarantee measures, nor any response measures of digital teaching resources. Simultaneously, nearly a quarter of schools temporarily purchased online courses or resources, which also showed that the foundation of digital teaching resources in these schools was insufficient. Others, such as extracurricular activities and campus culture, were not taken seriously. An in-depth analysis of the cases showed that less than a quarter of the schools carried out online extracurricular activities, and only a few schools were concerned about the construction of the school culture and the physical and mental development of students. Besides, the copyright of teaching resources was also critical. Among the series of policy documents formulated by schools, only a few have made the documents on online teaching resources' copyright protection. Only one of the 106 cases mentioned strengthened the copyright awareness of online resources.

\subsection{Suggestions on the future development of online learning}

The integration and innovation of the real economy and network economy is the development trend of industrial transformation and upgrading. Promoting the Internet plus vocational education is an inevitable choice for the development of modern vocational education. During the pandemic, it has been shown that the Internet maturity supported the essential operation of society under the condition of isolation and ensured the people's fundamental living needs. After the pandemic, relying on the Internet has become an irreversible trend. As industry upgrades, it is necessary to build a diversified, specialized, and lifelong vocational education system to adapt to China's industrial transformation requirements.

Information technology has changed the way of human cognition and learning. Vocational students are expected to use information technology to improve their information learning ability comprehensively and practical ability, cultivate their innovative spirit and lifelong learning ability to meet the times and future development needs. Based on the core literacy of learners, vocational education is bound to empower learners through technology innovation. The in-depth integration of technology and education can improve information literacy and the capabilities of vocational informatization and lifelong learning. This integration encourages learners to become digital citizens, knowledge builders, innovative designers, computational thinkers, creative communicators, and global collaborators. 
During the pandemic, most of the vocational teachers deepened the experience of using the Internet. The teaching philosophy, content, and method can cause revolutionary changes due to technology empowerment in the future. Teachers need to improve their ITbased teaching ability and creative ability with ICT (information and communication technology). They must also improve their information professional ability and sustainability to adapt to technological changes such as big data and artificial intelligence, leave their teaching comfort zone, and improve digital learning ability. Furthermore, such an ability helps them integrate technology into the teaching process and effectively promote teaching quality.

In 2002, the United Nations Educational, Scientific and Cultural Organization (UNESCO) issued a declaration calling for the joint development of Open Educational Resources (OERs), including complete courses, electronic textbooks, multimedia courseware, micro-lectures videos, electronic test questions, teaching materials, tool software, etc. Conforming to the trend of open educational resources and advocating the sharing of vocational educational resources, incredibly modular and material, can help teachers reorganize their own teaching needs. In terms of the construction of OERs in vocational education, virtual reality simulation is suggested to be an effective way out of the dilemma that vocational education lacks a practice environment. However, the development of virtual reality simulation training resources encounters many difficulties (e.g., high technical content, strong professionalism, meeting the requirements of post-ability training, large cost investment, long development cycle) that depend on various social forces. Therefore, the cooperation between schools and enterprises is a critical way for the development of vocational education.

Finally, the construction of a digital campus is the foundation and symbol of the development of modern vocational education. It enriches and expands the space for vocational education and guarantees the cultivation of skilled talents. The digital campus is an informatization environment where the online virtual campus and the actual physical campus are profoundly integrated and interactive. It supports vocational institutions to achieve differentiated teaching, personalized learning, refined management, and intelligent services, which promote the modernization of vocational institutions. The construction and application of digital campus in vocational education should take the development of technology literacy of teachers and students and employment ability as the core goal, which supports the reform of the technical system and organizational system. A modern digital campus environment can be constructed to promote a free and personalized learning atmosphere through value reconstruction, structure reorganization, process reengineering, cultural reconstruction, and mode innovation.

\section{Conclusion}

In the spring semester 2020, vocational institutions coped with the pandemic's outbreak through online learning and achieved the overall goal of "Not Going to School but Classes still Ongoing" set up by the Ministry of Education China. In summary, there were three powers behind this - first, the power of the system. From the Ministry of Education China to local education departments and then to various colleges and schools, the institutions timely informed, guided the training of online teaching effectively, and promoted actively sharing high-quality learning resources, which reflected the strong 
leadership of the Communist Party of China and the superiority of the socialist system. The country's systemic power was released at this critical juncture, supporting online education's smooth development. Second, school administrators and teachers demonstrated the power of responsibility. In the face of crises, they worked extra time without payment and devoted themselves to online learning. The third is the power of technology. Vocational institutions in China have made significant progress in constructing IT infrastructure in the past ten years. In particular, schools with a better foundation for digital campus construction have been relatively comfortable coping with online education during the pandemic. Meanwhile, vocational institutions can break the invisible "wall" and gain external technical help to support online learning, thanks to the Internet's rapid development.

However, online learning is only an emergency measure in response to the pandemic in most vocational institutions during the pandemic. As the saying goes, crisis entails opportunity; it should be realized that there are dynamic changes in the process of industrial society turning to the information society. The development of vocational education in the information age requires thinking actively about the reform path and strategy and putting it into action.

\section{References}

Assunção Flores, M., \& Gago, M. (2020). Teacher education in times of COVID-19 pandemic in Portugal: national, institutional and pedagogical responses. Journal of Education for Teaching, 1-10.

Benjamin Luke Moorhouse (2020) Adaptations to a face-to-face initial teacher education course 'forced' online due to the COVID-19 pandemic, Journal of Education for Teaching, 46:4, 609-611, DOI: $10.1080 / 02607476.2020 .1755205$

Carmen Carrillo \& Maria Assunção Flores. (2020). COVID-19 and teacher education: a literature review of online teaching and learning practices, European Journal of Teacher Education, 43:4, 466-487, DOI: 10.1080/02619768.2020.1821184

Choi, B., Jegatheeswaran, L., Minocha, A. et al.(2020). The impact of the COVID-19 pandemic on final year medical students in the United Kingdom: a national survey. BMC Med Educ 20, 206 (2020). https:// doi.org/10.1186/s12909-020-02117-1

Christakis DA, Van Cleve W, \& Zimmerman FJ. (2020). Estimation of US Children's Educational Attainment and Years of Life Lost Associated With Primary School Closures During the Coronavirus Disease 2019 Pandemic. JAMA Netw Open. 3(11):e2028786. doi:10.1001/ jamanetworkopen.2020.28786

Hebebci, M. T., Bertiz, Y., \& Alan, S. (2020). Investigation of views of students and teachers on distance education practices during the Coronavirus (COVID-19) Pandemic. International Journal of Technology in Education and Science (IJTES),4(4), 267-282.

Irene van der Spoel, Omid Noroozi, Ellen Schuurink \& Stan van Ginkel (2020) Teachers' online teaching expectations and experiences during the Covid19-pandemic in the Netherlands, European Journal of 
Teacher Education, 43:4, 623-638, DOI: 10.1080/02619768.2020.1821185

Johnson, N., Veletsianos, G., \& Seaman, J. (2020). U.S. faculty and administrators' experiences and approaches in the early weeks of the COVID-19 pandemic. Online Learning, 24(2), 6-21. https://doi. org/10.24059/olj.v24i2.2285

Lokanath Mishra, Tushar Gupta, \& Abha Shree. (2020). Online teaching-learning in higher education during lockdown period of COVID-19 pandemic.International Journal of Educational Research Open, Volume 1, https://doi.org/10.1016/ j.ijedro.2020.100012.

Moawad, R.A. (2020). Online Learning during the COVID-19 Pandemic and Academic Stress in University Students. Revista Romaneasca pentru Educatie Multidimensionala, 12(1Sup2), 100-107. https://doi.org/10.18662/ rrem/12.1 $\sup 1 / 252$

Pather, N., Blyth, P., Chapman, J.A., Dayal, M.R., Flack, N.A.M.S., Fogg, Q.A., Green, R.A., Hulme, A.K., Johnson, I.P., Meyer, A.J., Morley, J.W., Shortland, P.J., Štrkalj, G., Štrkalj, M., Valter, K., Webb, A.L., Woodley, S.J., Lazarus, M.D., 2020. Forced Disruption of Anatomy Education in Australia and New Zealand: An Acute Response to the Covid-19 Pandemic. Anatomical Sciences Education 13, 284 300.. doi:10.1002/ase. 1968

Soled, D., Goel, S., Barry, D., Erfani, P., Joseph, N., Kochis, M., Uppal, N., Velasquez, D., Vora, K., \& Scott, K. W. (2020). Medical Student Mobilization During a Crisis: Lessons From a COVID-19 Medical Student Response Team. Academic medicine : journal of the Association of American Medical Colleges, 95(9), 1384-1387. https://doi. org/10.1097/ACM.0000000000003401

Supriyanto, A., Hartini, S., Irdasari, W. N., Miftahul, A., Oktapiana, S., \& Mumpuni,
S. D. (2020). Teacher professional quality: Counselling services with technology in Pandemic Covid-19. Counsellia: Jurnal Bimbingan dan Konseling, 10(2), 176189.

Toquero, C. M. (2020). Challenges and Opportunities for Higher Education Amid the COVID-19 Pandemic: The Philippine Context. Pedagogical Research, 5(4).

\section{Acknowledgment}

The China National Social Science Grant funded this study for the project titled Theory Building and Empirical Study on Blended Learning (BCA180084). The authors are grateful to all participants for their contribution to the study, including Jiangang Cheng, Mingxuan Chen, Youru Xie, Liansheng Ge, Geping Liu, Zhixian Zhong, Yi Zhang, Shusheng Shen, Wei Wang, Wenlan Zhang, Yingqun Liu, Juan Yang, Yangyang Luo, Junfeng Diao, Hao Huang, Yiran Cui, Jian Sun, Biting Huang, Nan Chen, Jinjing Liu, Kaiyu Yi, etc. 